\title{
Factors Influencing the Interest Level of Secondary Students going into STEM fields and their parents' perceived interest in STEM (Evaluation)
}

Science, Technology, Engineering and Mathematics (STEM) disciplines are essential to society and to competing in the global economy [1]. The role of STEM education has evolved from providing students with STEM content knowledge and understanding, to preparing students to be interested in and committed to pursuing careers in the STEM workforce. According to the President's Council of Advisors on Science and Technology, "We must prepare all students, including girls and minorities, who are underrepresented in these fields, to be proficient in STEM subjects. And we must inspire all students to learn STEM and, in the process, motivate many of them to pursue STEM careers" [2]. According to the U.S. Department of Commerce, Economics and Statistics Administration, STEM workers drive the nation's innovation and competitiveness by creating new ideas, companies and industries. However, many U.S. businesses have concerns about the availability of STEM graduates [3]. Unfortunately, there is a lack of interest by students in the United States to enter STEM fields, particularly engineering [4] and [5].

Between 2000 and 2010, the growth in the STEM job market was three times that of non-STEM fields according to the Economics and Statistics Administration, and STEM jobs in the U.S. are projected to grow by $17 \%$ between 2008 and 2018 compared to $9.8 \%$ for non-STEM fields during the same period [3].

Outreach programs targeted at schools is one of the methods often used to improve student interest in STEM, and findings suggest that outreach programs are effective, especially for elementary school students [6]. Summer outreach programs, where students learn about engineering outside the school environment, have been largely successful in increasing student interest in STEM fields. Findings show that outreach programs targeted at the high school level generally raise awareness and yield more interest in engineering [7] - [10].

This paper reports on a summer outreach program conducted in 2017. This program was designed to provide under-resourced students in Utah with STEM experiences. The goal of the program was to increase student interest in pursuing engineering and other STEM undergraduate degrees.

\section{Program Description}

Students and science teachers from multiple school districts in Utah were invited to attend a weeklong summer engineering camp at the campus of Utah State University. This engineering camp is part of a 7-year GEAR UP project funded by the U.S. Department of Education. The grant's overall goal is to help more than 3,000 middle and high school students improve their academic achievement, creating a pipeline of academically prepared students enrolling and excelling in college. During the summer camp, teacher and student participants developed engineering research hypotheses, tested those hypotheses and presented results in a poster session. Participating teachers applied the research and engineering camp activities to develop classroom lessons for their science classroom to meet the Next Generation Science Standards 
(NGSS) framework which has engineering as a fundamental component. The number of participating students in the engineering camp was 33 and the number of teachers was 10.

Participant demographics for student participants is shown in Table 1 below.

Table 1. Demographics of student participants

\begin{tabular}{cc} 
Category & $\begin{array}{c}\text { Number } \\
\text { (Percentage) }\end{array}$ \\
\hline Age in years N (\%) & $2(5.5 \%)$ \\
13 & $33(91.7 \%)$ \\
14 & $1(2.7 \%)$ \\
15 & \\
Gender N (\%) & $15(41.6 \%)$ \\
Male & $21(58.3 \%)$ \\
Female & \\
Ethnicity N $(\%)$ & $28(77.7 \%)$ \\
White & $3(8.3 \%)$ \\
Asian & $4(11.1 \%)$ \\
Hispanic & $1(2.7 \%)$ \\
\hline
\end{tabular}

As to be expected, most of the students are the same age at 14 years old (eighth graders going into ninth grade). Most of the student participants are also from the White ethnicity (77.7\%). Hispanic students made $11.1 \%$ of the sample. Asians and Native Americans also made up 8.3\% and $2.7 \%$ of the population, respectively. Those numbers are comparable to the Census data for the state where the research was conducted.

The program was designed to promote hands-on learning with little passive classroom learning. The main theme of the engineering camp was water and environmental engineering. Before the camp activities started, students completed a pre-camp survey to determine their perceptions of and interest in STEM. The same survey was given to students at the end of the engineering camp to determine the impact the camp experience had on improving students' perceptions and interest in STEM.

The first day of the engineering camp included activities to pique the students' interest in using STEM activities to better manage water resources. The day began with an activity showing students the water cycle to illustrate the amount of available fresh water for human use in the hope of increasing their appreciation for the scarcity of usable water. The results of this activity showed up many times in the daily journals students wrote as they learned more about the importance of water conservation. 
The water cycle activity was followed by a fish tagging activity. This included how the fish tagging process was done, the importance of it, and how scientists and engineers use the process to determine the health of streams and movement of fish in the stream. With the aid of a graduate student in Fisheries Biology, students had the opportunity to engage in the practice of tagging fish.

During the second day of the engineering camp students visited three sites along a river in a local water shed. The first stop was upstream in the mountains where the river is fed from melting snow. The second stop was downstream of camping, fishing, kayaking and other recreational uses of the water at a point just before the river enters the city. The final stop was after the river had passed through the city, farms and ranches in the area. At each stop, students took various physical and chemical measurements of the water including temperature, flow velocity and volume, dissolved oxygen, turbidity, and nutrient concentrations including phosphates and nitrates. The students also collected and characterized macro invertebrates living in the river. The point of this activity was to assess what happens physically, chemically, and biologically to the water as it flows downstream, passes through a city, and changes in response to the influence of human civilization.

The third day of the engineering camp focused on storm water impacts and water treatment. This included a simulated storm water activity comparing runoff volume and intensity as rainfall was simulated on an area covered in vegetation and another area covered with asphalt/concrete to show the impact of urban development (increases in impervious surface areas). The students then visited a parking lot storm water system at a local chain box store and observed the plants used to filter pollutants running off of the parking lot such as oil/gas. Those pollutants get washed away by the rain, but before the water enters the storm water system, it passes through this thick vegetation area and is cleaned by specialized plants. Students also had the opportunity to see what happens as a non-reactive fluorescent tracer (simulated pollution) is dumped into the local river and observed how fast and how far pollution can spread. Finally, teams of students competed at building a water filter from sand and gravel. Faculty and student researchers judged the quality of the filters based on the clarity of the filtered water as well as the speed at which the filter worked.

The fourth day of the engineering camp focused on wastewater treatment plants. Students looked at bacteria under the microscope and saw some of the bacteria that are at work at biological treatment plants such as the ones they would visit later that day. After learning about bacteria related to treatment plants, students visited a local treatment lagoon and wetland system that filters the water of the surrounding county and then visited and sampled and analyzed water quality at another mechanical treatment plant. The students learned the differences, advantages, and disadvantages of natural and mechanical treatment methods.

During the final day (Day 5) of the engineering camp, students presented what they had learned in a poster session followed by a presentation session. Finally, students completed a post-survey to gauge their interest gains in STEM through the camp. 
Table 2 below shows a summary of the activities students and teachers engaged in during the week-long engineering camp.

Table 2. Outline of the weeklong engineering camp

\begin{tabular}{|c|c|c|c|c|}
\hline Day & Activity 1 & Activity 2 & Activity 3 & Activity 4 \\
\hline Monday & Water Cycle & Fish tagging & & \\
\hline Tuesday & \multicolumn{4}{|c|}{$\begin{array}{l}\text { Measuring water properties at multiple locations along a local river, starting upstream and } \\
\text { then going all the way downstream. }\end{array}$} \\
\hline Wednesday & $\begin{array}{l}\text { Water Run off } \\
\text { experiment }\end{array}$ & $\begin{array}{l}\text { Storm water } \\
\text { impacts/multiple } \\
\text { location }\end{array}$ & River Dye activity & $\begin{array}{l}\text { Building and } \\
\text { testing a water } \\
\text { filter }\end{array}$ \\
\hline Thursday & $\begin{array}{l}\text { Looking at bacteria } \\
\text { under a } \\
\text { microscope }\end{array}$ & $\begin{array}{l}\text { Site visit to local } \\
\text { lagoons treatment } \\
\text { facility, sampling and } \\
\text { analysis of water } \\
\text { quality parameters }\end{array}$ & $\begin{array}{l}\text { Site visit to local } \\
\text { mechanical waste } \\
\text { water treatment } \\
\text { facility, sampling } \\
\text { and analysis of } \\
\text { water quality } \\
\text { parameters }\end{array}$ & \\
\hline Friday & Poster Session & Presentation Session & & \\
\hline
\end{tabular}

\section{Data Collection}

\section{Students' Pre and Post-surveys}

The first day students arrived at the engineering camp they completed a pre-survey which contained demographic questions and the STEM-CIS Career Interest Survey, based on the work of Kier, Blanchard, Osborne, \& Albert [11]. This survey measures the attitudes and interest of students towards STEM fields and has four sections, each pertaining to one part of STEM. Each section includes 11 questions for a total of 44 questions. The STEM CIS includes questions such as "I am interested in careers that involve engineering". The survey is a 5-point Likert scale from 'Strongly Agree' to 'Strongly Disagree'. The pre-survey also included four questions regarding peer attitude to science. These four questions were based on the work of Talton and Simpson [12] and included statements such as "My best friend likes science." Responses were on a 5-point Likert scale ranging from 'Strongly Agree' to 'Strongly Disagree.' More questions were drawn from the work of Franz-Odendaal, Blotnicky, French, \& Joy [13] and targets students' engagement with STEM activities. Questions such as "Which of the activities listed below have you participated in in the past year? (You can choose more than one)" were included. These questions were used to understand the level of student engagement with informal STEM activities.

The students' involvement in these activities was evaluated with respect to the degree of engagement as follows: No STEM engagement, low level of STEM engagement (visits to science centers/museums/zoos), moderate level of STEM engagement (specialized group visited their class/ after school STEM club), and high STEM engagement (involved in a STEM program/competition/fair). This was based on the work by Franz-Odendaal et al. [13]. 
All of these are factors that potentially influence student interest in STEM fields and the data were collected in an attempt to understand the effect of these factors on students' interest. At the completion of the engineering camp, students, once again, completed the post-survey. The pre and post-surveys contained the same set of questions concerning interest in STEM and factors that potentially influence their interest in STEM. The post-survey also included students' ratings of the various activities in the camp.

\section{Data Analysis}

The pre-survey and post-survey data from the STEM CIS were analyzed via a statistical package (SPSS) looking for changes in significance between the pre and post-surveys for students' interest. The total number of students was $\mathrm{N}=33$.

A significance test (Two Tailed Student's T-Test) was conducted for the entire pool of students and another set of tests was conducted on the students who started below average on interest in STEM to see if they had larger gains than the entire group. The cutoff point was 3 and lower on the 5-point Likert scale as 3 is neutral and 2 is disagree and 1 is strongly disagree. This is based on the work of Hernandez et al. [14]. Additionally, since participation in the camps was voluntary, on average it was expected that participants came to the camp with an interest in science as observed by Aschbacher, Ing, \& Tsai [15]. An examination of the students that came with low interest in science gave a more accurate indication of the success of the camp in improving interest in STEM.

Based on the data collected from the STEM CIS surveys, correlations were examined between the level of interest and various factors that possibly influence student interest such as parent perceptions, friend attitudes and level of STEM engagement.

The nature of this research involved students who volunteered to participate, which explains their high initial interest in STEM [15]. Additionally, the GEAR UP program targets students from low-income families. Those two factors indicate that the sample is not random or representative of the total population of Utah or the United States of America. Thus, the data cannot be generalized to the population of the state and thus inference statistics will only explain the differences between pre and post camp data but will not be used to draw inferences about the population [16].

\section{Results}

Results from the quantitative data are presented in two categories; Inference and descriptive statistics between the pre and post data and correlation analysis.

\section{Inference and Descriptive Statistics}

This section presents the data from students in the form of inference and descriptive statistics between the pre and post-surveys. 


\section{STEM Interest}

The following is the analysis of the students' interest in STEM careers, and STEM fields in general.

Table 3. Inference and Descriptive Statistics related to students' perception of STEM. Questions where there is a significant difference have their P-value in bold font.

\begin{tabular}{lcccc}
\hline \multirow{2}{*}{ Question } & \multicolumn{2}{c}{ Mean } & Standard & \multirow{2}{*}{ P value } \\
& Pre & Post & Deviation & \\
\hline I am interested in careers that use science & 3.78 & 4.00 & 0.98 & 0.1610 \\
I am interested in careers that use mathematics & 3.69 & 4.12 & 0.75 & $\mathbf{0 . 0 0 3 0}$ \\
I am interested in careers that use technology & 3.91 & 4.24 & 0.79 & $\mathbf{0 . 0 1 9 0}$ \\
I am interested in careers that involve engineering & 3.94 & 4.12 & 0.64 & 0.1100 \\
I plan to use STEM in my future career & 3.93 & 4.17 & 0.54 & $\mathbf{0 . 0 1 4 0}$ \\
I am interested in careers that involve STEM & 3.82 & 4.12 & 0.53 & $\mathbf{0 . 0 0 3 0}$ \\
STEM interest average & 3.92 & 4.07 & 0.31 & $\mathbf{0 . 0 0 8 0}$ \\
\hline
\end{tabular}

As can be seen in Table 3, there was a significant upward change in students' interest and perception of STEM careers on average. There was an upward trend in the students' interest, which was clear when looking at the average of all the categories. There is an upward trend in the students' interest when looking at the average of all 44 questions under STEM where the pvalue was a significant 0.008 despite the small number of students. Additionally, the questions " $I$ am interested in careers that use mathematics," "I am interested in careers that use technology," "I plan to use STEM in my future career," "I am interested in careers that involve STEM" all had a significant change with $\mathrm{p}$ values of $0.003,0.019,0.014$ and 0.008 , respectively. The categories that did not have a significant change related to interest in science and engineering careers had $\mathrm{p}$ values of 0.161 and 0.11 , respectively, which are close to significant despite the small number of students.

To show trends more clearly, bar charts were created for each question. The values were changed from a Likert scale to a percentage to make the chart easier to read. Figure 1 shows the trends of students' interest in the various STEM fields before and after the camp. This chart shows students' interest increasing in all STEM fields between the pre and post camp surveys. 


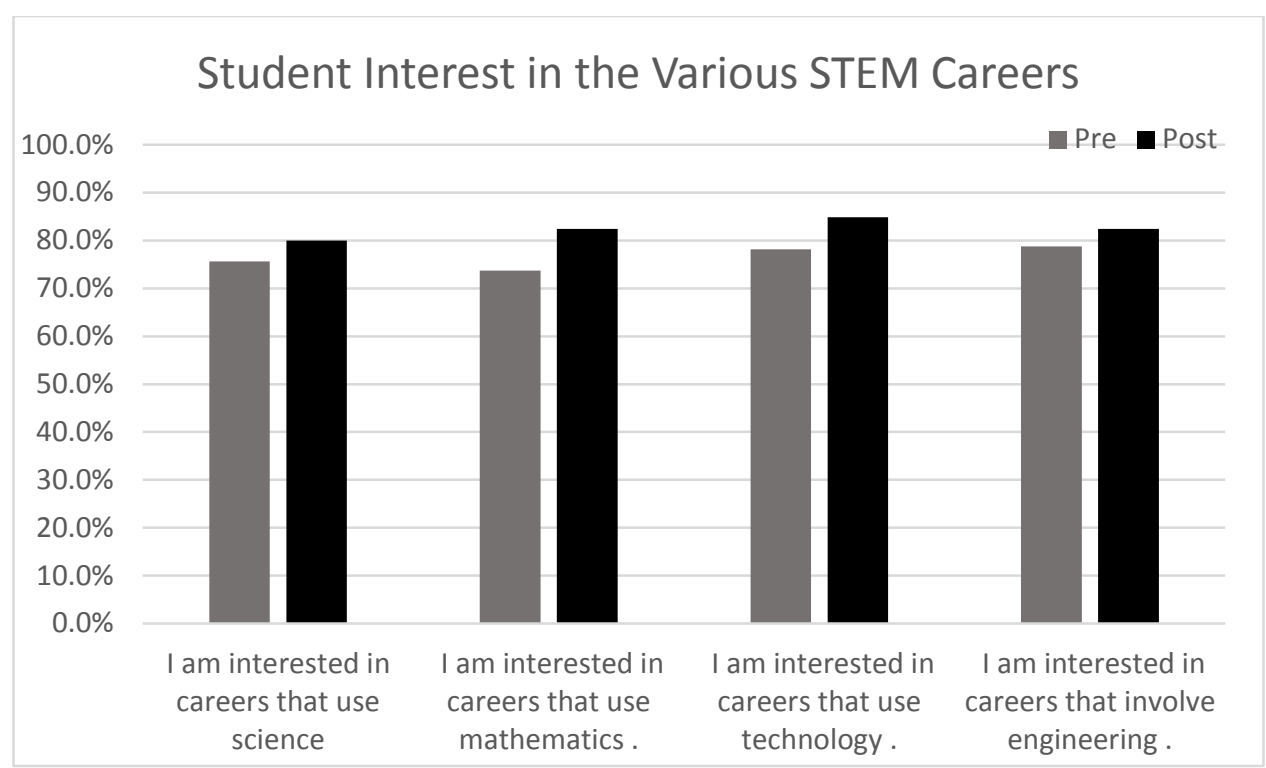

Figure 1: Students' interest in the various STEM careers, Pre and Post Camp as a percentage converted from a 1-5 Likert Scale

Figure 2 shows a bar chart of averaged questions related to STEM careers in the survey. This chart shows an upward trend from pre to post when it comes to students' perception of STEM careers and as a field.

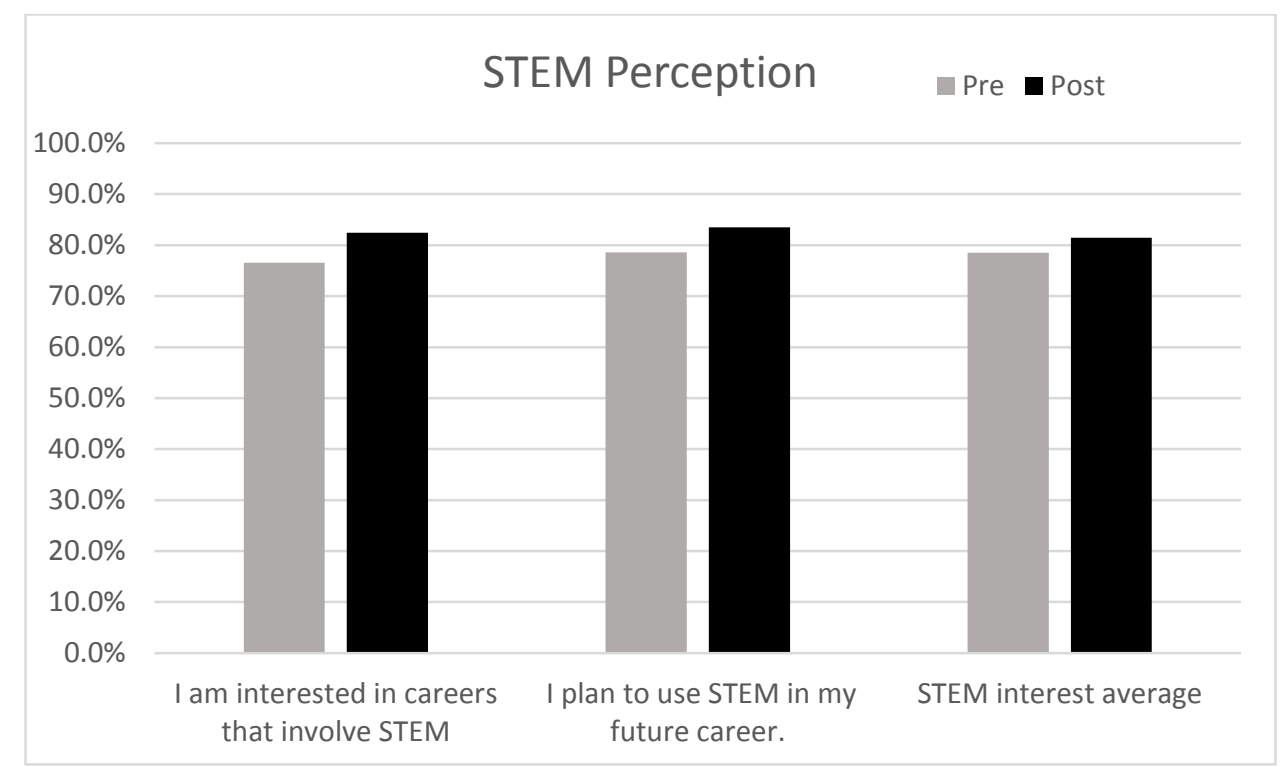

Figure 2: Students' Perception of STEM Pre and Post Camp as a percentage converted form a 1-5 Likert Scale

STEM interest for the sub group that started with low interest

The following section discusses a sub group which includes student participants who started the camp with low interest levels of 3 or less on the Likert scale, which corresponds to neutral or 
less. Those students also ended the camp with an increased interest level of 4 or 5 on the Likert scale, which are Agree and Strongly Agree respectively. The number of students with low interest in the pre-survey and then high interest in the post-survey differed based on the questions in Table 3. The sample size for this sub group ranged between $5-9$ students.

Table 4. Inference and Descriptive Statistics related to students' STEM career interest. Questions where there is a significant difference have their P-value in bold font. The students started with low interest and ended with high interest.

\begin{tabular}{lcccc}
\hline \multirow{2}{*}{ Question } & \multicolumn{2}{c}{ Mean } & Standard & \multirow{2}{*}{ P value } \\
\cline { 2 - 4 } & Pre & Post & Deviation & \\
\hline I plan to use science in my future career & 3.00 & 4.14 & 0.37 & $\mathbf{0 . 0 0 0}$ \\
I am interested in careers that use science & 3.00 & 4.33 & 0.52 & $\mathbf{0 . 0 0 1}$ \\
I plan to use mathematics in my future career & 2.80 & 4.00 & 0.45 & $\mathbf{0 . 0 0 4}$ \\
I am interested in careers that use mathematics & 2.57 & 4.00 & 0.79 & $\mathbf{0 . 0 0 3}$ \\
I plan to use technology in my future career & 3.00 & 4.33 & 0.57 & 0.057 \\
I am interested in careers that use technology & 2.60 & 4.20 & 0.89 & $\mathbf{0 . 0 1 6}$ \\
I plan to use engineering in my future career & 2.77 & 4.11 & 0.71 & $\mathbf{0 . 0 0 0}$ \\
I am interested in careers that use engineering & 3.00 & 4.44 & 0.55 & $\mathbf{0 . 0 0 5}$ \\
\hline
\end{tabular}

As can be seen in Table 4, the change in student STEM career interest as reflected in all but one question was significant. There was an upward trend in the low interest students' interest in careers in STEM fields. The only question that was not significant is "I plan to use technology in my future career" with a p-value of 0.057 . The same category had a p-value of 0.4470 when looking at the full sample of students.

Additionally, the questions "I am interested in careers that use science" and "I am interested in careers that use engineering" changed from p-values of 0.161 and 0.11 respectively for the full sample, to having significant p-values when looking at the students starting with low interest where the p-values for those two questions became significant 0.001 and 0.000 respectively. This suggests that the intervention appears to have been more effective for the students who started with low interest in those fields.

The rest of the questions were significant in both the full sample and the sub-group. This shows that the sub group that started with low interest had more gains in interest in STEM fields.

To show trends more clearly, bar charts were created for each question. Figures 3 and 4 show bar charts of career-related questions for both the full sample and the subgroup. The first figure is for Science and Mathematics while the second figure is for Technology and Engineering. The values were changed from a Likert scale to a percentage to make the charts easier to read. These charts show the differences in gain for the full sample versus the sub group that started with low interest. The sub group that started with low interest made much greater gains in interest compared to the rest of the group. 


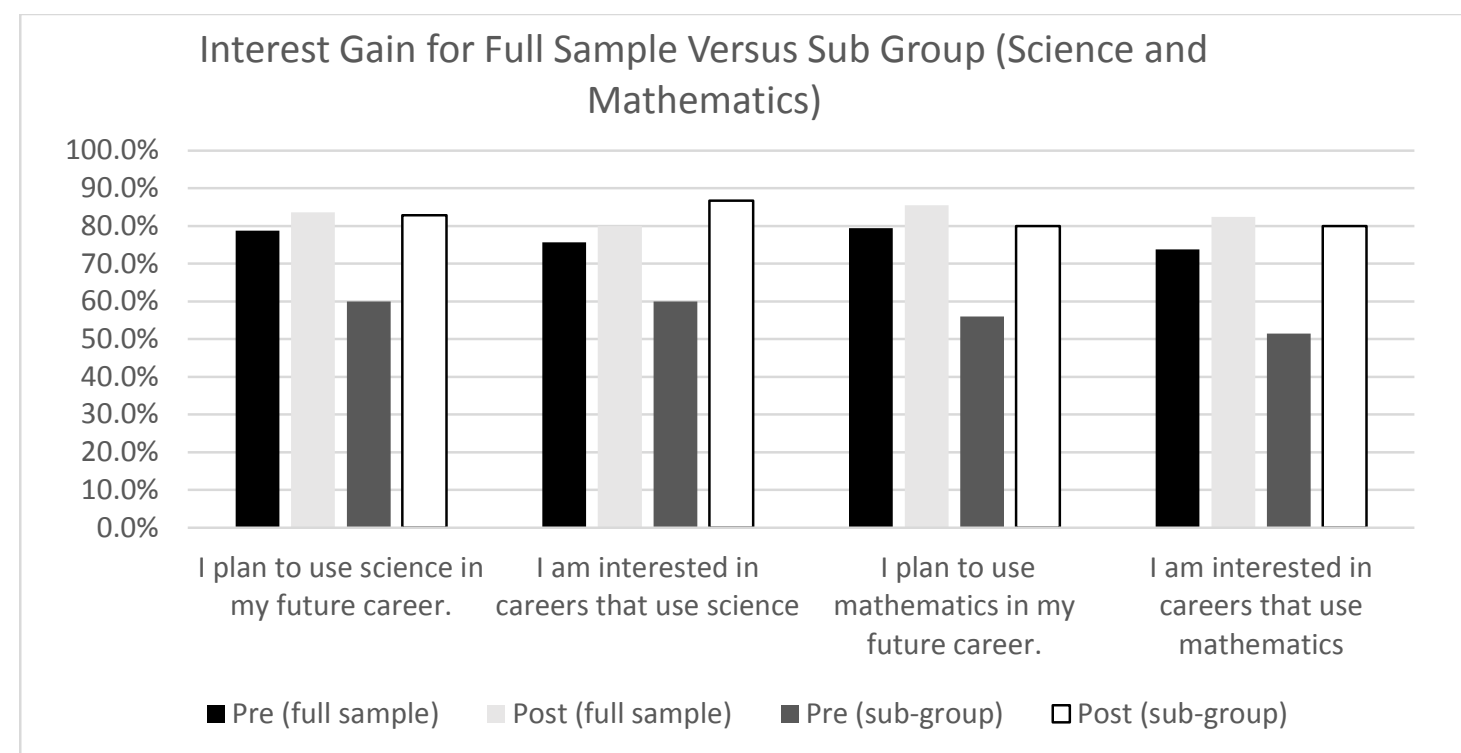

Figure 3: Students Perception (shown as a percentage) of Science and Mathematics Pre and Post Camp for both the full sample and the sub group that started with low interest

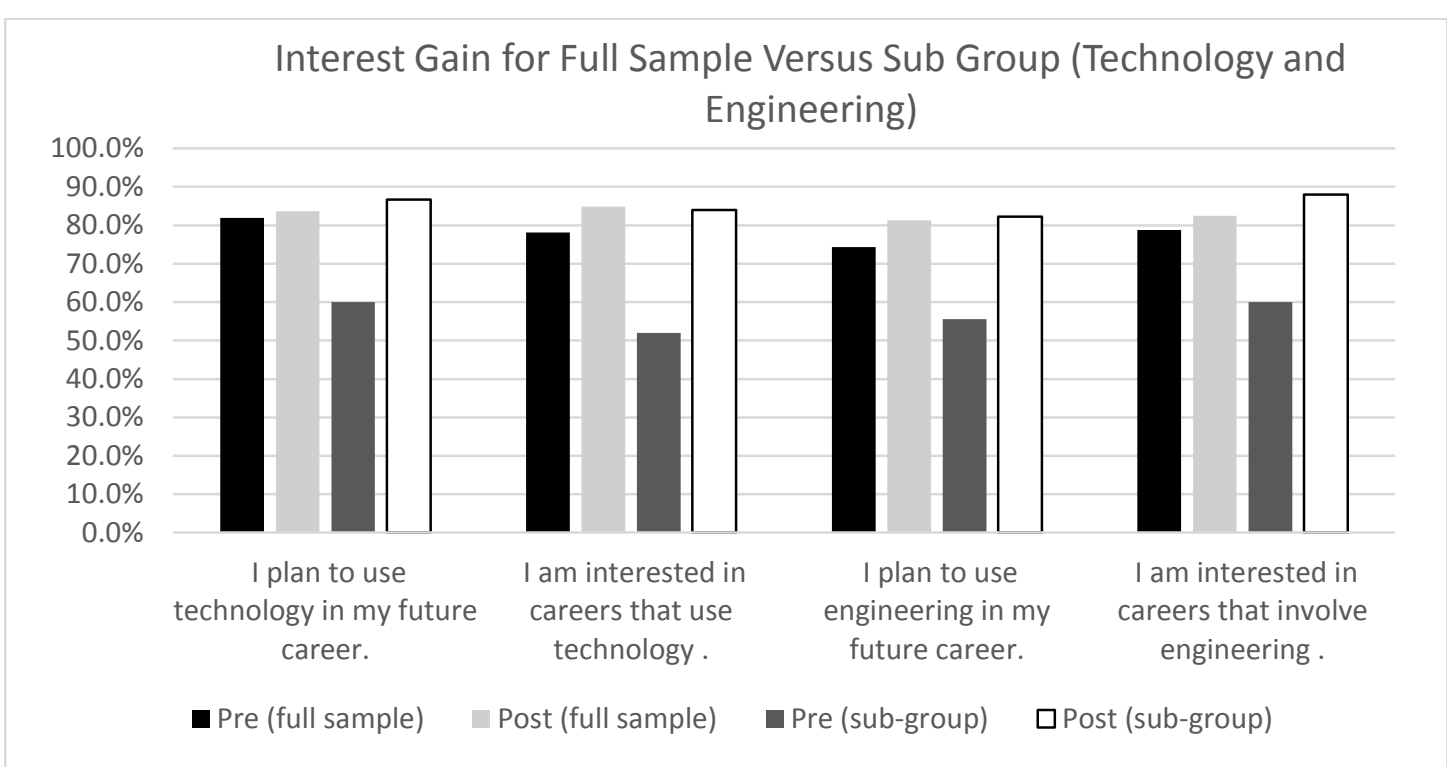

Figure 4: Students Perception (shown as a percentage) of Technology and Engineering Pre and Post Camp for both the full sample and the sub group that started with low interest 
The following is the results of students' interest in the various fields of STEM broken down by gender as can be seen in Table 5 .

Table 5. Inference and Descriptive Statistics related to male vs female students' STEM career interest. Questions where there is a significant difference have their P-value in bold font.

\begin{tabular}{lccccccc}
\hline \multirow{2}{*}{ Question } & \multicolumn{3}{c}{ Mean Male Interest } & \multicolumn{3}{c}{ Mean Female Interest } \\
& Pre & Post & P-Value & Pre & Post & P-Value \\
\hline $\begin{array}{l}\text { I am interested in careers that involve science } \\
\text { I am interested in careers that involve }\end{array}$ & 3.92 & 4.00 & 0.165 & 3.67 & 4.00 & 0.286 \\
$\begin{array}{l}\text { mathematics } \\
\begin{array}{l}\text { I am interested in careers that involve } \\
\text { technology }\end{array}\end{array}$ & 3.64 & 4.00 & 0.096 & 3.72 & 4.22 & $\mathbf{0 . 0 1 5}$ \\
$\begin{array}{l}\text { I am interested in careers that involve } \\
\text { engineering }\end{array}$ & 4.07 & 4.20 & 0.435 & 3.77 & 4.27 & $\mathbf{0 . 0 2 4}$ \\
$\begin{array}{l}\text { I am interested in careers that involve STEM } \\
\text { a }\end{array}$ & 3.91 & 4.07 & 4.07 & 0.583 & 3.88 & 4.17 & 0.135 \\
\hline
\end{tabular}

As can be seen in Table 5, female students experienced a higher gain in interest between the pre and the post test. Females started the camp with lower interest than males in all the categories except mathematics. At the end of the camp, females had gained more interest in all the fields and ended the camp with equal or higher interest than males in all the fields. Significant increases in interest for females include mathematics, technology and STEM careers. This is even more impressive considering the small sample size of 18 female students. Males also had a small sample size of 15 and only one category proved significant between the pre and the post, this category is the average interest in all STEM fields with a P-value of 0.019 .

To show those trends more clearly, a bar chart was created to show the differences in gain for the males versus females. Females show a greater interest gain in all the categories. The values were changed from a Likert scale to a percentage to make the chart easier to read. 


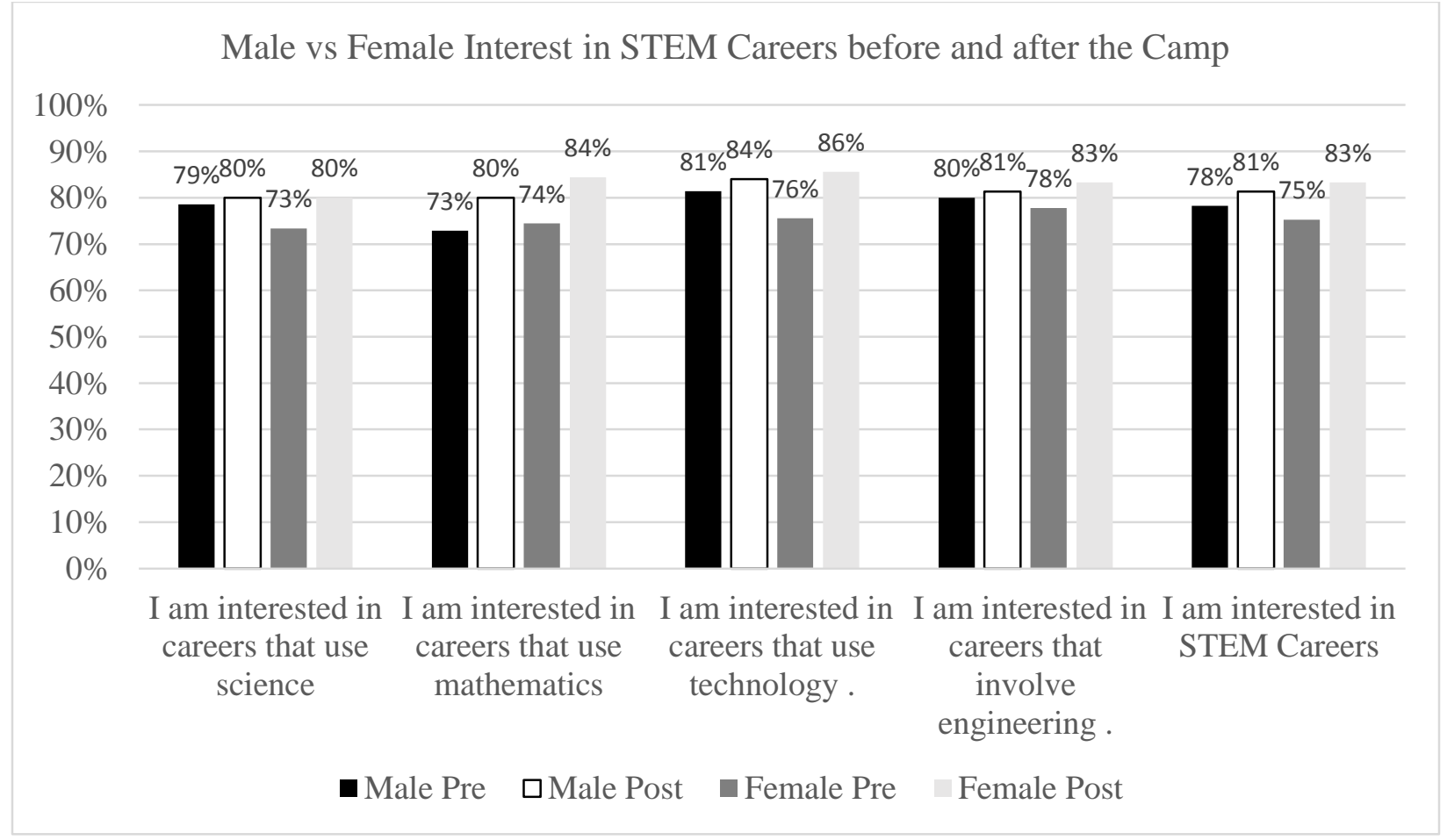

Figure 5: Students Perception of Science and Mathematics (shown as a percentage) Pre and Post Camp for both males and females

\section{Parent Perceptions}

The following is the results of the parents' surveys. Similar to students, parents completed surveys before and after the camp. Unlike students, not the same parents completed the pre- and post-surveys. Those surveys were sent in both electronic format via e-mail with multiple reminders as well as paper versions via mail or sent with the students at the conclusion of the camp. The pre-surveys were completed by 38 parents while the post-survey was completed by 23 parents.

Table 6. Inference and Descriptive Statistics related to parents' perception of STEM

\begin{tabular}{|c|c|c|c|c|}
\hline \multirow{2}{*}{ Question } & \multicolumn{2}{|c|}{ Mean } & \multirow{2}{*}{$\begin{array}{l}\text { Standard } \\
\text { Deviation }\end{array}$} & \multirow{2}{*}{$P$ value } \\
\hline & Pre & Post & & \\
\hline Parents' math perception & 4.61 & 4.83 & 0.64 & 0.08 \\
\hline Parents' science perception & 4.73 & 4.69 & 0.50 & 0.74 \\
\hline Parents' math and science perception average & 4.67 & 4.77 & 0.51 & 0.38 \\
\hline I believe engineering improves our quality of life & 4.76 & 4.92 & 0.54 & 0.15 \\
\hline I want my child(ren) to pursue a career in engineering & 4.15 & 4.42 & 0.83 & 0.22 \\
\hline $\begin{array}{l}\text { I think it is equally important for both boys and girls } \\
\text { to learn engineering }\end{array}$ & 4.78 & 4.83 & 0.53 & 0.73 \\
\hline Parents' engineering perception average & 4.57 & 4.72 & 0.47 & 0.17 \\
\hline
\end{tabular}


As can be seen in Table 6 above, none of the results from the parents' surveys were significant. This can be attributed to two factors; the parents had very high perceptions of STEM fields with most of these questions yielding results averaging more than 4.5 on a 5-point scale. The other factor was the small sample size especially in the post-survey with less parents participating in that survey. However, the trends are positive with most of the questions showing higher averages on the post-survey than the pre-survey.

Of particular interest for this research is the question "I want my child(ren) to pursue a career in engineering" which experienced a change from 4.15 on the pre-survey to 4.42 on the postsurvey. While this change was not significant due to the small sample size, it is still the largest numerical change in the parents' surveys. This leads us to believe that this kind of camp/intervention and parental involvement increases parents' likelihood to want to have their children to pursue a career in engineering.

\section{Correlations and factors influencing student interest in STEM}

This section explores the factors influencing student interest in the various fields in STEM. The correlations were calculated using SPSS software using Pearson's correlation and the interpretation was based on Cohen's [17] social sciences rule of thumb to identify strong and weak correlations. A correlation that is above 0.5 is considered strong, $0.3-0.5$ is considered moderate and 0.1-0.3 is considered a weak correlation.

In this section the correlation coefficients between STEM career interest and various factors are presented in table 7 followed by a discussion of the results. 
Table 7. Correlation coefficients between various factors and the career interest in STEM. Bold correlations are significant.

\begin{tabular}{lcc}
\hline \multicolumn{1}{c}{ Factor } & \multicolumn{2}{c}{ I am interested in careers } \\
& that involve STEM \\
& Pre & Post \\
\hline Working hard at STEM activities/classes & $\mathbf{0 . 6 7 5}$ & $\mathbf{0 . 6 4 5}$ \\
If I do well in STEM classes and activities, it will help me in my & $\mathbf{0 . 8 2 9}$ & $\mathbf{0 . 8 9 2}$ \\
future career. & $\mathbf{0 . 6 0 3}$ & $\mathbf{0 . 5 2 9}$ \\
My parents would like it if I choose a STEM career. & $\mathbf{0 . 5 8 4}$ & $\mathbf{0 . 7 1 4}$ \\
I like activities that involve STEM & 0.114 & -0.022 \\
I have a role model in a STEM career. & 0.140 & 0.028 \\
I am able to get a good grade in my science class & $\mathbf{0 . 6 6 2}$ & $\mathbf{0 . 4 8 3}$ \\
I am able to get a good grade in my mathematics class & $\mathbf{0 . 6 3 0}$ & $\mathbf{0 . 7 6 0}$ \\
I am able to do well in activities that involve engineering. & $\mathbf{0 . 7 1 1}$ & $\mathbf{0 . 6 1 5}$ \\
STEM grades and activities & $\mathbf{0 . 8 6 5}$ & $\mathbf{0 . 8 2 3}$ \\
Overall interest in STEM & 0.235 & 0.232 \\
STEM camps attended & 0.139 & 0.215 \\
Level of STEM engagement & 0.071 & 0.031 \\
First time participating in STEM-related activities & 0.258 & $\mathbf{0 . 6 0 7}$ \\
Friends' perception of science & 0.454 & 0.203 \\
Parents' perception of math & 0.178 & 0.383 \\
Parents' perception of science & -0.064 & 0.052 \\
Parents' perception of engineering & $\mathbf{0 . 4 1 4}$ & -0.001 \\
Parents' Education & 0.104 & -0.157 \\
Parents' Income & & \\
\hline
\end{tabular}

As shown in Table 7, the strongest correlations with regard to interest in STEM careers appears to be the students' perceptions, interest, and perceived abilities in STEM areas. Some strong correlations of note include "STEM grades and activities" "If I do well in STEM classes and activities, it will help me in my future career," "I like activities that involve STEM" and the overall interest in STEM obtained by averaging the 44 questions about interest in STEM with correlation coefficients of $0.615,0.892,0.714$ and 0.823 , respectively, the four of which are very strong correlations. Interestingly, the factor "STEM camps attended" stayed at a consistent 0.23 moderate correlation from the pre- to post-survey.

Other interesting factors include the students' ability to get a good grade in their science and mathematics classes and do well in engineering activities. Those factors produced a range between weak and strong correlations. In the post- camp survey, science and math had correlation coefficients of 0.028 and 0.483 , respectively while engineering had a correlation coefficient of 0.760 . 
Friends' perception of science had a strong correlation, especially in the post- camp survey, with a correlation coefficient of 0.607 . Since all the students attending the camp experienced increased interest in STEM, that could explain why at the post camp survey, peer perception seemed to be a stronger factor than it was at the beginning of the camp.

Interestingly, parental influence was weaker in comparison to other factors with their perception of science, math and engineering having weak to moderate correlations with correlation coefficients of $0.203,0.383$ and 0.052 . Parent education and income also did not play a strong role with very weak correlations. However, students' perception of how their parents would think of a STEM career had a strong correlation with the factor "My parents would like it if I choose a STEM career" having a correlation coefficient of 0.529 .

\section{Conclusions}

Students who came to the camp with low interest in STEM careers gained more than the students who started with high interest. This leads us to believe that a good way to conduct future camps is to try and target the students who have average or low interest in STEM, not the students who had already made up their minds on a career in STEM. This may be challenging as participating in those kinds of camps is voluntary and the students who participate generally do so due to their interest in STEM. However, working closely with parents, teachers and students can aid in finding out which students have low interest and to try to recruit those students to attend these camps. Students starting with low interest having significant gains compared to their peers who started with high interest is similar to the findings by [15].

STEM recruitment is critical for the economy and society. In a study by [18] the results of their surveys show that students who participated in outreach program have more interest in going into STEM fields. Abaid, Kopman and Porfiri [7] observed similar results and they concluded that summer workshops where students learn about engineering outside the school environment have been largely successful in increasing interest in STEM fields. The importance of STEM recruitment was stressed by Yates [9] and Paulino, Babb, Saar, Friesen and Brandon [8], and their findings were similar to the other studies. They concluded that outreach programs targeted at the high school level generally raises awareness and yields more interest in engineering. Similar results were found by Yilmaz, Ren, Custer and Coleman [10].

Looking at correlation coefficients, it became clear that students' overall interest in STEM, as well as their perceived ability to do well in STEM, were chief among strong correlations. Additionally, how much they liked participating in those activities also played a strong role in their perceptions and interest. Another strong factor was the perception of their friends. This also leads us to believe that working with students who are interested in STEM to convince their friends who are not interested to join these kinds of camps may be a powerful recruiting tool.

Interestingly, factors that are often touted as strong influences on a student's choice of career were not very strong in this study. Those include; parents' perception, income and education, 
level of STEM engagement, the first time the students had engaged in STEM and role models. This is similar to results found by a recent college-level study sponsored by Microsoft Corporation [19]. They found that students having a passion for STEM and studying hard were the most important factors affecting their interest in STEM. The authors also found that external factors including mentors and role models were actually less important.

This study is part of a 7-year project with the intention of following students from middle school all the way to college. While one of the objectives of this project is to find out whether attending summer camps increases interest in STEM, it also has the objective of finding out whether this interest is sustained all the way to college, and whether or not it plays a role in the students' choice of a college major. This is the second year of this project and similar camps will take place every summer for the next 5 years. At the end of this longitudinal study, more data will be available to develop a more informed conclusion about the effectiveness of summer STEM camps in bolstering the STEM pipeline and getting more students to choose STEM careers.

\section{References:}

[1.] National Academy of Sciences, National Academy of Engineering, and Institute of Medicine. Rising Above the Gathering Storm, Revisited: Rapidly Approaching Category 5: Washington, DC: The National Academies Press. (2010)

[2.] President's Council of Advisors on Science and Technology (PCAST). Prepare and inspire: K-12 education in Science, Technology, Engineering, and Math (STEM) for America's future. White House Office of Science and Technology Policy (OSTP), Washington, DC. Retrieved April 7, 2017 from https://www.nsf.gov/attachments/117803/public/2a--Prepare_and_Inspire-PCAST.pdf. (2010).

[3.] D. Langdon, G. McKittrick, D. Beede, B. Khan, \& M. Doms. "STEM: Good jobs now and for the future." Washington, DC: U.S. Department of Commerce, Economics and Statistics Administration. (2011).

[4.] M. F. Kazmierczak. "Losing the Competitive Advantage? The Challenge for Science and Technology in the United States." Washington, DC: Ae A, Advancing the Business of Technology, 2005.

[5.] D. Callahan and L. Callahan, "Looking for Engineering Students? Go Home," IEEE Transactions on Education, vol. 47, no. 4, pp. 500-501, 2004.

[6.] A. M. Johnson, G. Ozogul, M. D. Didonato, and M. Reisslein, "Engineering perceptions of female and male K-12 students: effects of a multimedia overview on elementary, middle-, and high-school students," European Journal of Engineering Education, vol. 38, no. 5, pp. 519-531, 2013. 
[7.] N. Abaid, V. Kopman and M. Porfiri, "An Attraction Toward Engineering Careers: The Story of a Brooklyn Outreach Program for KuFFFD12 Students," IEEE Robotics \& Automation Magazine, vol. 20, no. 2, pp. 31-39, June 2013.

doi: 10.1109/MRA.2012.2184672

[8.] A. Paulino, P. Babb, C. Saar, S. Friesen, and J. Brandon, "Engaging high school students in an engineering thermodynamics project," IEEE Global Engineering Education Conference (EDUCON), 2014.

[9.] J. K. Yates, “Engineering Careers Case Study: K-12 Recruitment Initiative," Leadership and Management in Engineering, vol. 13, no. 1, pp. 3-10, 2013.

[10.] M. Yilmaz, J. Ren, S. Custer, and J. Coleman, "Hands-On Summer Camp to Attract K-12 Students to Engineering Fields," IEEE Transactions on Education, vol. 53, no. 1, pp. 144-151, 2010 .

[11.] M. W. Kier, M. R. Blanchard, J. W. Osborne, and J. L. Albert, "The Development of the STEM Career Interest Survey (STEM-CIS)," Research in Science Education, vol. 44, no. 3, pp. 461-481, 2013.

[12.] E. L. Talton and R. D. Simpson, "Relationships of attitudes toward self, family, and school with attitude toward science among adolescents," Science Education, vol. 70, no. 4, pp. 365-374, 1986.

[13.] T. A. Franz-Odendaal, K. Blotnicky, F. French, and P. Joy, "Experiences and Perceptions of STEM Subjects, Careers, and Engagement in STEM Activities Among Middle School Students in the Maritime Provinces," Canadian Journal of Science, Mathematics and Technology Education, vol. 16, no. 2, pp. 153-168, Feb. 2016.

[14.] P. R. Hernandez, R. Bodin, J. W. Elliott, B. Ibrahim, K. E. Rambo-Hernandez, T. W. Chen, and M. A. D. Miranda, "Connecting the STEM dots: measuring the effect of an integrated engineering design intervention," International Journal of Technology and Design Education, vol. 24, no. 1, pp. 107-120, May 2013.

[15.] P. R. Aschbacher, M. Ing, and S. M. Tsai, "Is Science Me? Exploring Middle School Students' STE-M Career Aspirations," Journal of Science Education and Technology, vol. 23, no. 6, pp. 735-743, Jun. 2014.

[16.] A. J. Hayter, Probability \& Statistics for Engineers and Scientists, $4^{\text {th }}$ Edition. Cengage Learning, 2005.

[17.] J. W. Cohen, Statistical power analysis for the behavioral sciences. New York: Academic Press, 1977. 
[18.] J. Laut, T. Bartolini, and M. Porfiri, "Bioinspiring an Interest in STEM," IEEE Transactions on Education, vol. 58, no. 1, pp. 48-55, 2015.

[19.] Microsoft Corporation. "STEM perceptions: student \& parent study." Retrieved April 7, 2017 from

https://news.microsoft.com/download/archived/presskits/citizenship/docs/STEMPercepti onsReport.pdf. Retrieved March, 2017. (2011). 